\title{
Hybrid Composites from Wheat Straw, Inorganic Filler, and Recycled Polypropylene: Morphology and Mechanical and Thermal Expansion Performance
}

\author{
Min Yu, ${ }^{1}$ Runzhou Huang, ${ }^{2}$ Chunxia He, ${ }^{3}$ Qinglin $W u,{ }^{4}$ and Xueni Zhao ${ }^{1}$ \\ ${ }^{1}$ College of Mechanical \& Electrical Engineering, Shaanxi University of Science \& Technology, Xian 710021, China \\ ${ }^{2}$ College of Materials Science and Engineering, Nanjing Forestry University, Nanjing 210037, China \\ ${ }^{3}$ Jiangsu Key Laboratory for Intelligent Agricultural Equipment, College of Engineering, Nanjing Agricultural University, \\ Nanjing 210031, China \\ ${ }^{4}$ School of Renewable Natural Resources, Louisiana State University Agricultural Center, Baton Rouge, LA 70803, USA
}

Correspondence should be addressed to Runzhou Huang; runzhouhuang@gmail.com

Received 25 November 2015; Revised 31 January 2016; Accepted 16 February 2016

Academic Editor: Hom N. Dhakal

Copyright (c) 2016 Min Yu et al. This is an open access article distributed under the Creative Commons Attribution License, which permits unrestricted use, distribution, and reproduction in any medium, provided the original work is properly cited.

Reinforcing effect of hybrid filler including wheat straw (WS) and inorganic filler (heavy calcium carbonate, silicon dioxide, and fly ash) in recycled polypropylene (R-PP) has been investigated. The effects of individual filler (WS) and combined fillers (WS and inorganic filler) on morphological, mechanical, and thermal expansion and water absorption properties of hybrid composites were investigated. The flexural modulus and flexural strength were both reduced when reinforced with three kinds of inorganic fillers, respectively, which was possibly due to the poor interphase adhesion as observed in SEM. The high surface energy of heavy calcium carbonate due to its high acidic character provides an opportunity of better PP-heavy calcium carbonate interfacial interactions compared to PP-straw, PP-fly ash, and $\mathrm{PP}-\mathrm{SiO}_{2}$ interface. The water absorption at saturation increased markedly by introduction of WS in it. The hybrid composites from WS and inorganic fillers showed better water absorption compared to those WS/PP composites. The thermal expansion of composites decreased with the increase of WS loading. Heavy calcium and $\mathrm{SiO}_{2}$ can obviously reduce the LCTE value of composite. At the $25 \%$ inorganic filler content, composites had the smallest LCTE values.

\section{Introduction}

Wood plastic composites (WPCs) are gaining a great attention in different applications due to their good properties, which include low density, low cost, renewability, and mechanical properties. Apart from this, their exposure to changing environment or contact with aqueous media has made it necessary to evaluate the thermal expansion and water uptake characteristics of these materials [1].

A growing demand for structural WPCs elements characterized by low thermal expansion and water uptake has recently appeared in applications such as curved structure design, where minimum dimension change and water absorption are required. Thus, thermal expansion and water absorption caused by external environment variations have to be taken into account in the design of WPCs for final application [2]. Linear coefficients of thermal expansion (LCTE) values for wood (along the grain) and mineral (e.g., calcium carbonate) fillers are about 20 times lower than those of plastics and about 10 times lower than those of WPCs [3]. Lee et al. [4] studied thermal and mechanical properties of wood flour (WF) and talc filled polylactic acid (PLA) composites. The addition of WF and WF-TALC mixture into neat PLA resulted in some decreases in the glass transition and crystallization temperatures of the composites. Hybrid composites from talc, WF, and polyhydroxybutyrateco-valerate (PHBV) were analyzed by Singh et al. [5], which shows the composition at 20 wt.\% of wood fiber and talc in PHBV gave a leap of $200 \%$ improvement in Young's and flexural modulus. To enhance the physicomechanical properties of WPCs, Nourbakhsh et al. investigated the performance of polypropylene composites made from hybrid fillers including 
rice husk flour, beech bard flour, and nano- $\mathrm{SiO}_{2}$ [6]. The results suggest that waste lignocellulose materials along with mineral filler (nano- $\mathrm{SiO}_{2}$ ) can be successfully utilized to make composites with useful physicomechanical properties. Composites with $58 \mathrm{wt} . \%$ lignocellulose flour and $3 \mathrm{wt} . \%$ nano- $\mathrm{SiO}_{2}$ loading showed optimum water absorption in all combinations.

In order to create a balance among the environmental friendliness, the cost effectiveness, and the characteristics of the green composites, the compositional selection and design of hybrid composites play an important role [7]. China is a large agricultural country which produces thousands of tons of wheat. As an agricultural by-product, most of WS was directly abandoned which made WS very cheap and easily obtained [8]. Usually, the addition of inorganic filler into polymeric materials enhances the stiffness, toughness, and dimension stability of filled composites. Although inorganic fillers like glass fibers, carbon fibers, or nanofillers have been reported to enhance the mechanical properties and thermal performance of filled plastic composites, their high price made the filled plastic composites more expensive [9, 10]. Heavy calcium carbonate, silicon dioxide, and fly ash are cheap and common inorganic materials. Heavy calcium carbonate is made by ground natural carbonate minerals such as calcite, marble, and limestone. Silicon dioxide is the main raw material of madding glass and pottery. Fly ash is the most common solid waste in power plant. The low cost and ease of use in processing make them a profitable material to the processing industry. The objective of this study is to develop recycled PP based hybrid composites consisting of WS and inorganic fillers. Three types of inorganic fillers (heavy calcium carbonate, silicon dioxide, and fly ash) were used for compounding with WS. The effects of individual filler (WS) and combined fillers (WS and inorganic filler) on morphological, mechanical, and thermal expansion and water absorption properties of composites were investigated. This composites system of WS and inorganic fillers reinforced recycled PP is expected to be a fundamental base for developing new functional applications of industrial and agricultural waste recycling. By proper combination, one can achieve a balance of properties such as high stiffness, good dimension stability, and low price.

\section{Materials Processing and Experiment Methods}

2.1. Raw Materials and Experimental Design. PP film was obtained from Jieliya Products Co., Jiangsu, China. WS came from Youfang Town, Jiangsu Province, China, which was ground by a LH-08B Speed Grinder (Xinchang Hongli, CNC Instruments Inc., Jiangsu, China) and screened by a 60 -mesh $(250 \mu \mathrm{m})$ screen. Before preparation, WS were first ovendried at $105^{\circ} \mathrm{C}$ for $6 \mathrm{~h}$ to reduce moisture content level to less than $2 \%$. Inorganic filler explored in this study included fly ash, silicon dioxide, and heavy calcium carbonate. The fly ash was supplied by Nanjing Jufeng Advanced Materials Co., China, and its particle size was 400 mesh $(38 \mu \mathrm{m})$ and 1250 mesh $(13 \mu \mathrm{m})$, respectively. Silicon dioxide and heavy calcium carbonate were supplied by Nanjing Zhining New
Materials Co., China, and their mesh size was 400 and 1250, respectively. Silane coupling agent (KH550) from Yaohua Co. (Shanghai, China) was utilized to treat WS and inorganic filler.

Experiment design included two factorial experiments. The first experiment was designed to study the effect of WS loading levels consisting of four loading rates (i.e., 20, 35, 50, and $60 \mathrm{wt} . \%)$. The second experiment was designed to study the effect of inorganic fillers (i.e., fly ash, silicon dioxide, and heavy calcium carbonate) and their loading level (i.e., 10, 15, 20 , and $25 \mathrm{wt} . \%)$ on inorganic filled WS/PP composites: R$\mathrm{PP} /$ fillers $=50 / 50$ (wt.\%) is fixed for all composites.

2.2. Sample Preparation. A speed mixer (K600-3205, Braun Electric, Germany) was used to mix WS and inorganic filler thoroughly, while stirring an aqueous solution (ethanol : water $=9: 1$ by weight) including a silane coupling agent ( $2 \mathrm{wt} . \%$ by the weight of WS and inorganic filler) was sprayed into them at $25^{\circ} \mathrm{C}$ for $30 \mathrm{~min}$. After that, the mixture of WS and inorganic filler was dried at $105^{\circ} \mathrm{C}$ for $12 \mathrm{~h}$. The inorganic filled WS/PP composites were prepared by blending the mixture and $\mathrm{PP}$ at $175^{\circ} \mathrm{C}$ for $5-7$ min on a two-roll mill (X-160 Banbury Mixer, Chuangcheng Rubber and Plastic Machinery Co., Ltd., Wuxi, China), after which the melting mixture acquired (XLB-0 Vulcanizing Machine, Shunli Rubber Machinery Co., Ltd., Huzhou, China) was ground into a compression molding machine at $180^{\circ} \mathrm{C}$ and 12.5 MPa for $12 \mathrm{~min}$ to shape it to a rectangular board.

\subsection{Characterization}

2.3.1. Morphology Analysis. The morphologies of selected composite samples were analyzed by a Hitachi S- 4800 Scanning Electron Microscope (SEM) (Hitachi Ltd., Tokyo, Japan). The fractured surfaces of selected test samples were coated with $\mathrm{Au}$ to improve the surface conductivity before observation and observed at an acceleration voltage of $3000 \mathrm{~V}$.

2.3.2. Mechanical Properties. Flexural test of samples was carried out according to ASTM D790-03, using a CMT6104 SANS Mechanical Testing Machine (Tesla Industrial systems Co., Guangdong, China). Notched izod impact strengths were measured with XJJ-5 Impact Tester (Jinjian Testing Instrument Co., Chengde, China) according to the ASTM D256-05. Four samples of each group were tested.

2.3.3. Water Absorption. Water absorption studies were performed following the ASTM D570-98. Three specimens (50 $\times 10 \times 5 \mathrm{~mm}$ ) of every sample were immersed in distilled water at room temperature. At various time intervals, test specimens were removed from water and weighed in a high precision balance. The content of water was calculated by the weight difference.

2.3.4. Thermal Expansion Performance. Thermal expansion samples were machined with a miniature table saw along the long direction of samples with a dimension of 43.5 (length) $\times 12.7$ (width) $\times 5.4$ (thickness) $\mathrm{mm}$. The LCTE value of 
each specimen was measured parallel to the long direction over a temperature range from 20 to $-13^{\circ} \mathrm{C}$ and from -13 to $60^{\circ} \mathrm{C}$. They were conditioned at $60^{\circ} \mathrm{C}$ in an oven and at $-13^{\circ} \mathrm{C}$ in a freezer from their initial equilibrium temperature of $25^{\circ} \mathrm{C}$ prior to size measurements with a Mitutoyo digimatic indicator of $\pm 0.01 \mathrm{~mm}$ accuracy (Mitutoyo Co., Kanagawa, Japan). Five specimens were used for each group. The LCTE for each sample was calculated based on size changes before and after conditioning. The heating and cooling rates were kept constant at $5^{\circ} \mathrm{C} / \mathrm{min}$. The $\operatorname{LCTE}\left(\alpha_{L}, 1 /{ }^{\circ} \mathrm{C}\right)$ was calculated as follows:

$$
\alpha_{L}=\frac{1}{L} \frac{d L}{d T},
$$

where $L$ is the linear dimension of the test sample and $d L / d T$ is the rate of change in the linear dimension per unit temperature.

\section{Results and Discussion}

3.1. Morphology. Morphologies of impact fractured surfaces of composites with WS and combined WS-inorganic fillers are shown in Figure 1. Some fiber pullout and inorganic filler debondings caused by poor interface adhesion between fillers and PP matrix happened during the fracture process as indicated by the voids on the fracture plane. As it can be seen from Figure $1(\mathrm{c}), \mathrm{SiO}_{2}$ and WS distribution into the matrix is reasonably well and, in contrast with Figures 1(a), 1(e), and $1(\mathrm{~g})$, more filler pullout and debondings were observed, indicating the lack of enough interfacial bonding strength. It could be found that most WS and heavy calcium carbonate appeared to be well dispersed in the PP matrix (Figure 1(c)), indicating that WS and heavy calcium carbonate were compounded well with PP matrix. Likewise, agglomeration of fillers was observed when filler content reached higher loading level as shown in Figure 1(h), which reduced their effective bonding.

This was consistent with low mechanical properties due to inefficiency of strength transfer from filler to plastic matrix.

\subsection{Mechanical Properties}

3.2.1. Flexural Property. Flexural properties of WS/PP composite with different loading level of WS from 20 to $65 \mathrm{wt} . \%$ are shown in Figure 2. Flexural modulus of the composite exhibited an increasing trend with increasing WS content in the WS/PP composites. WS/PP composite having 65 wt. $\%$ of WS content showed a notable increase of $45 \%$ when compared with $20 \mathrm{wt} . \%$. This phenomenon can be attributed to the fact that the WS fibers restrict the mobility of the macromolecules of the PP matrix when subjected to the tensile stress. It exhibited the high stiffness of WS which plays an important role in determining the flexural modulus. Flexural strength of WS/PP composite increased with WS content from 20 to $50 \mathrm{wt}$ \% but decreased at $65 \mathrm{wt} . \%$. This is because the higher content of WS fiber led to agglomeration problem. The agglomeration of WS fiber is an indication of poor bonding or low interfacial adhesion strength between the filler and PP matrix. Figure 2 also gives the details of WS/PP composites with varying inorganic filler level in matrix. The flexural modulus and flexural strength of $\mathrm{WS} / \mathrm{PP}$ composites were both reduced when reinforced with three kinds of inorganic fillers, respectively. The detrimental effect of inorganic filler addition into WS/PP composites became apparent such that inorganic filler reduced the ductile behaviour of the matrix by making the composites more brittle. In addition, the hydrophilic nature of the WS fiber and inorganic filler and the contrasting hydrophobic nature of PP matrix exacerbate the agglomeration problem as observed in the micrographs (Figure 1), thus resulting in the strength concentration and the reduction of bending property.

3.2.2. Impact Strength. The effect of WS content on the impact strength of WS/PP composites is depicted in Figure 3(a). A general trend of decreased impact strength with the increasing fiber content in a composite was observed. The stiffness of WS/PP composite increased with the addition of WS and the strength concentration caused by fiber aggregation, thus resulting in the reduced toughness of the composite. Figure 3 also shows the impact strength of the $\mathrm{WS} / \mathrm{PP}$ composites with inorganic fillers content from 10 to 25 wt. \%. The increase of inorganic filler loading with decreasing impact strength. The impact test measures the energy required to completely break the specimen. This energy is a combination of crack initiation and crack propagation phenomenon, which depends on various factors like fiber to matrix adhesion, toughness of matrix and fiber alone, defects in the packing of fiber/matrix, crystalline morphology, and so forth [11]. The WS and inorganic filler are stiffness materials and the increase of rigid inorganic filler further decreases the impact strength. The strength concentration caused by defects in the packing of filler/matrix may also be a contributing factor to reduced impact strength of the composites.

3.3. Surface Energy Analysis. For all fillers reinforced composite materials, the adhesion between the fillers and matrix has a key effect on the mechanical performance of the composites. Studies have indicated that good adhesion can benefit the load transfer between the fillers and matrix, determining the effectiveness of fillers in enhancing the mechanical properties and fracture behaviour of the composites [12, 13]. The surface energy of polymer could be used to study the wettability of polymer blending and the reinforcement with fibers, which govern the fillers and matrix adhesion properties. The level of adhesion is dependent on surface tension and interphase tension between the fillers and matrix. Surface energy data allows the calculation of theoretical work of adhesion values across an interface between fibers and another material $[14,15]$. The surface free energy was calculated according to the Lifshitz-van der Waals or Lewis acid/base theory $[5,16,17]$ :

$$
\gamma=\gamma^{\mathrm{LW}}+\gamma^{\mathrm{AB}}=\gamma^{\mathrm{LW}}+2\left(\gamma^{+} \gamma^{-}\right)^{1 / 2},
$$

where $\gamma$ is the surface energy (or surface tension in $\mathrm{mJ} / \mathrm{m}^{2}$ ). The superscript LW corresponds to the Lifshitz-van der Waals 


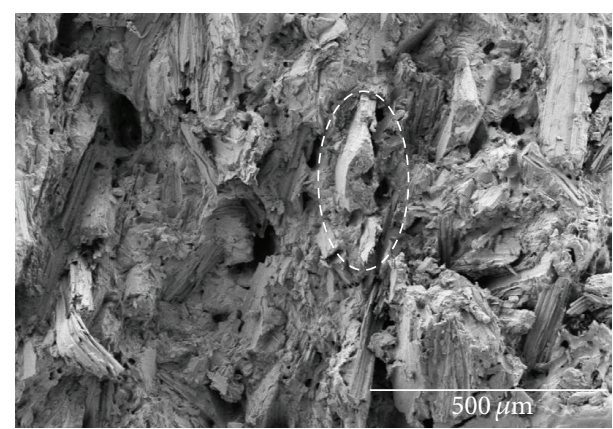

(a)

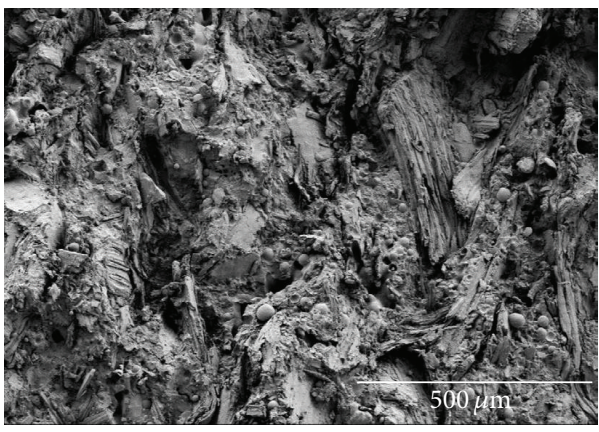

(c)

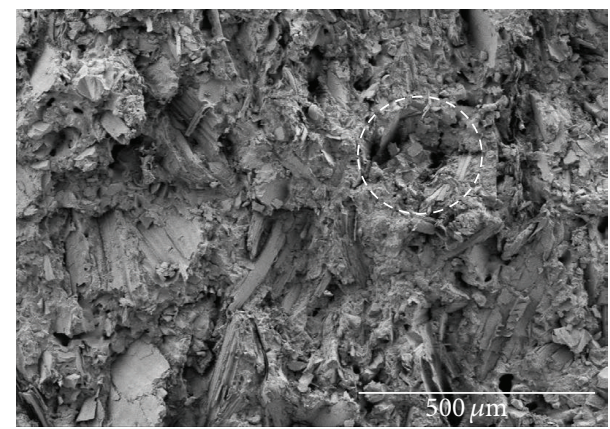

(e)

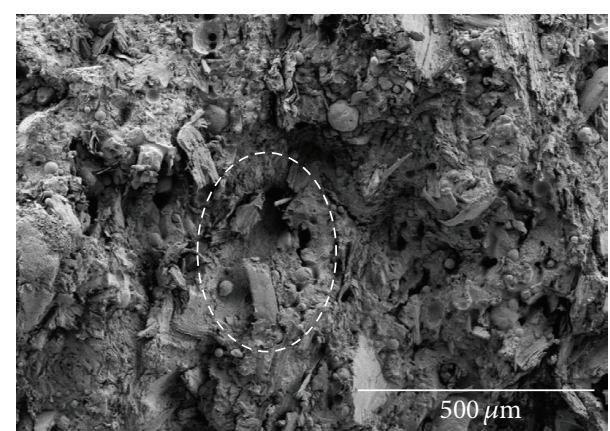

(g)

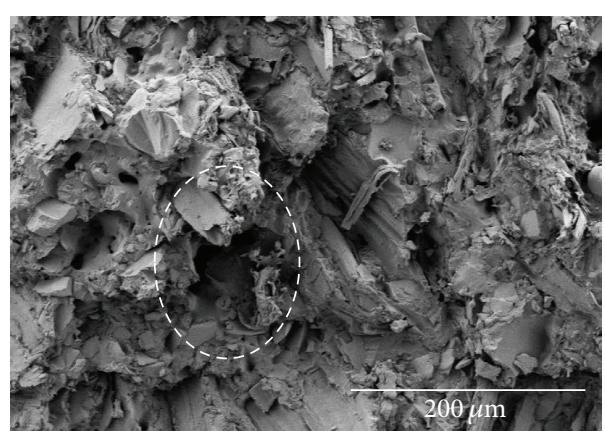

(b)

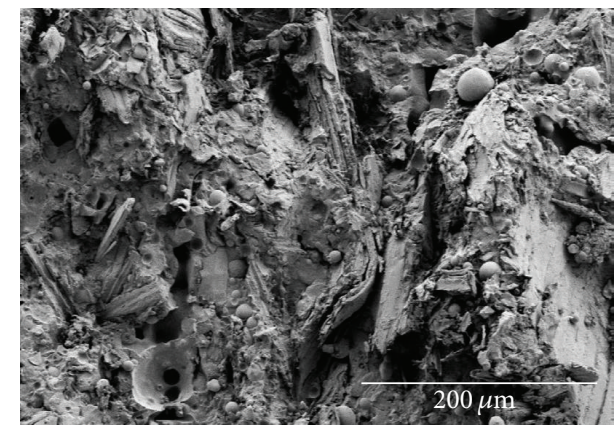

(d)

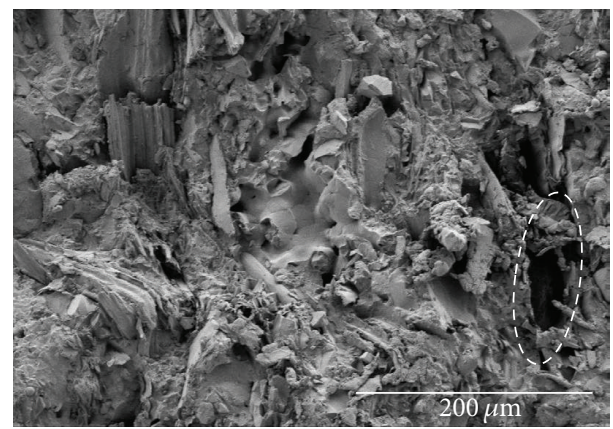

(f)

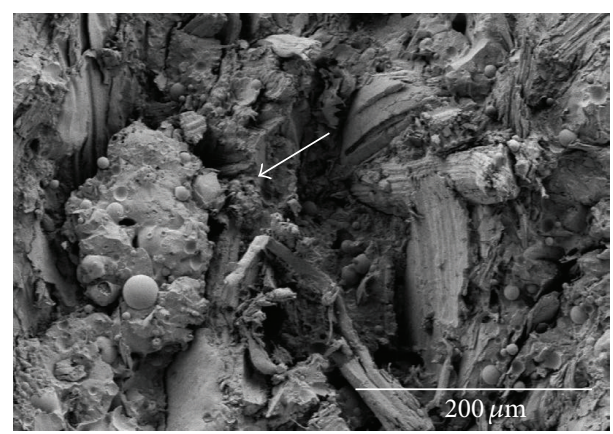

(h)

FIGURE 1: Morphology of fractured surfaces of composites with WS and combined fillers at 50\% loading level. First chart, (a) and (b) 50\% WS; and other three charts, $25 \%$ WS and 25\% inorganic filler: (c) and (d) heavy calcium carbonate, (e) and (f) silicon dioxide, and (g) and (h) fly ash. 


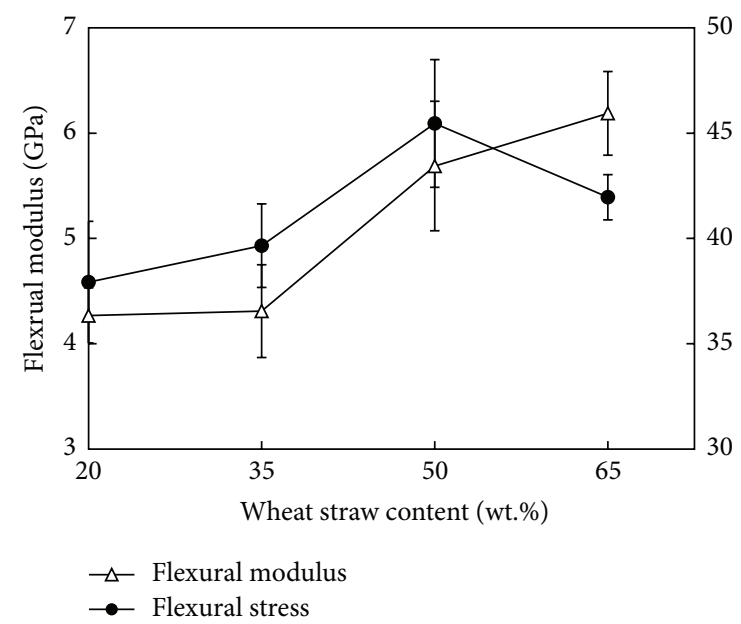

(a)

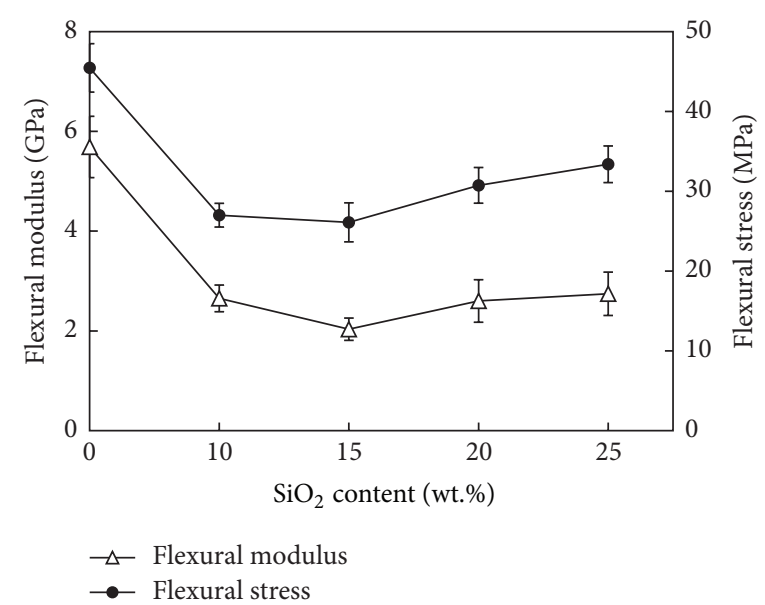

(c)

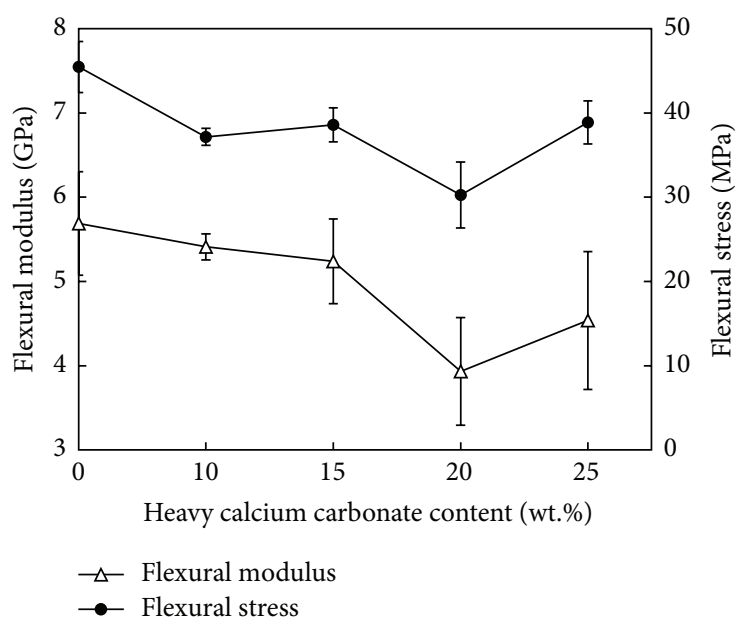

(b)

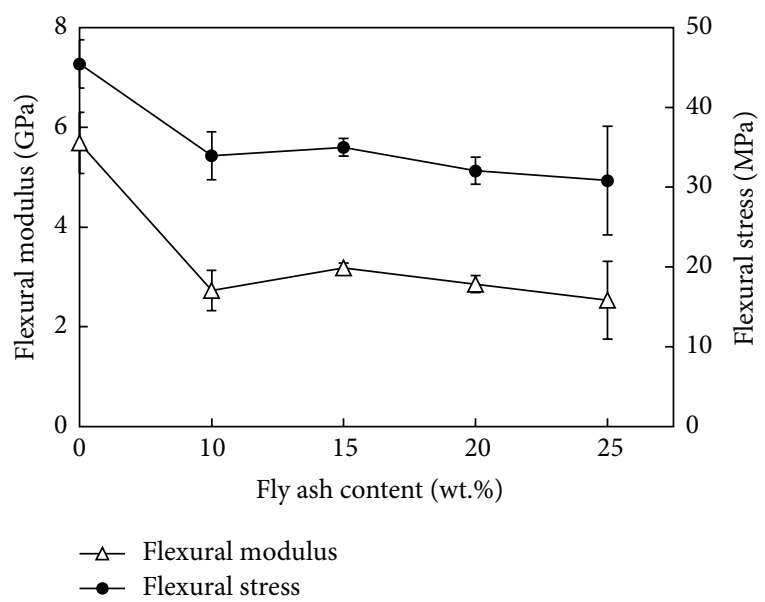

(d)

FIGURE 2: Flexural property of WS filled PP composites (a) and WS and inorganic filler reinforced PP composites, (b) heavy calcium carbonate, (c) silicon dioxide, and (d) fly ash.

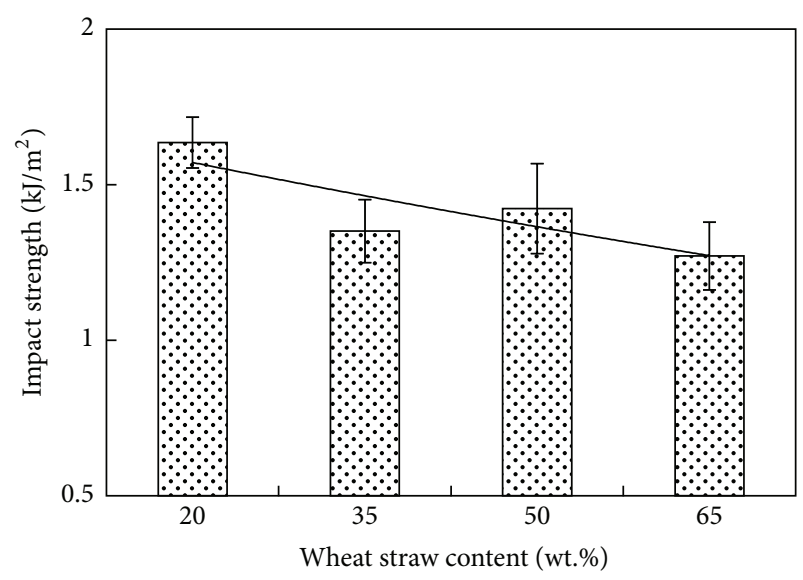

(a)

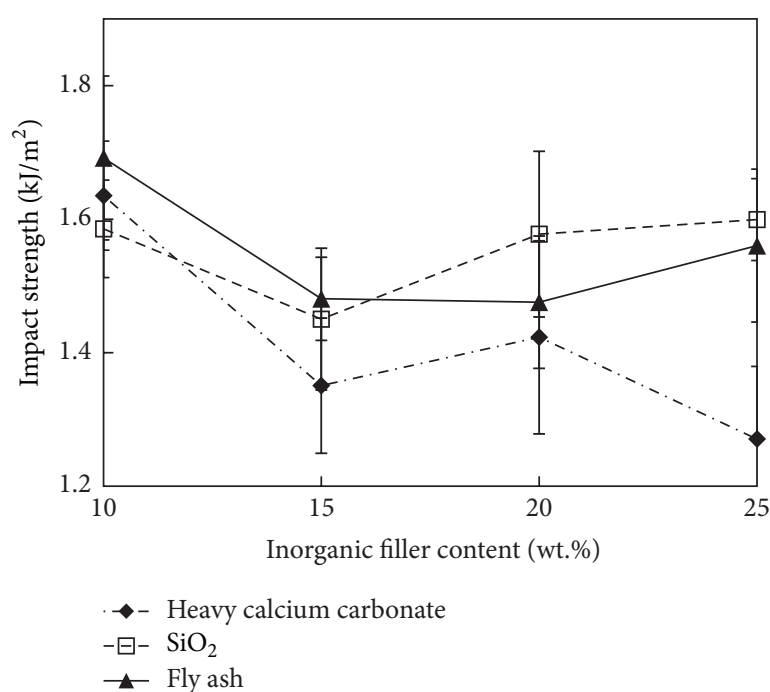

(b)

FIGURE 3: Impact strength of (a) WS filled PP composites and (b) WS and inorganic filler reinforced PP composites. 
TABLE 1: Surface energy parameters of PP and fillers.

\begin{tabular}{|c|c|c|c|c|c|}
\hline & $\gamma(\mathrm{mJ} / \mathrm{m})$ & $\gamma^{\mathrm{LW}}(\mathrm{mJ} / \mathrm{m})$ & $\gamma^{+}(\mathrm{m} J / \mathrm{m})$ & $\gamma^{-}(\mathrm{mJ} / \mathrm{m})$ & $\gamma^{\mathrm{AB}}(\mathrm{mJ} / \mathrm{m})$ \\
\hline PP & 28 & 24 & 0.02 & 1.1 & 0.3 \\
\hline $\mathrm{SiO}_{2}$ & 35.4 & 33.5 & 0.6 & 1.7 & 2.02 \\
\hline Fly ash & 21.8 & 20.9 & 0.45 & 0.45 & 0.9 \\
\hline Heavy calcium carbonate & 46.68 & 43.83 & 0.07 & 29 & 2.85 \\
\hline Straw & 34.5 & 26 & 4.25 & 4.25 & 8.5 \\
\hline
\end{tabular}

TABLE 2: Calculated interfacial energy and thermodynamical work of adhesion.

\begin{tabular}{lcc}
\hline Interface type & $\gamma_{i j}\left(\mathrm{~mJ} / \mathrm{m}^{2}\right)$ & $\mathrm{WA}\left(\mathrm{m} / \mathrm{m}^{2}\right)$ \\
\hline $\mathrm{PP}_{-} \mathrm{SiO}_{2}$ & 1.11 & 58.27 \\
PP-fly ash & -0.29 & 45.83 \\
PP-heavy calcium carbonate & 4.03 & 66.72 \\
PP-straw & 3.93 & 53.15 \\
\hline
\end{tabular}

component (apolar or dispersive component), which is based on temporary forces of attraction and repellence due to the movement of electrons in all molecules. $\gamma^{\mathrm{AB}}$ is Lewis acid/base or polar component, which is based on electron acceptor/electron donor interactions between polar moieties, so it can be further refined into the electron-acceptor $(\gamma+)$ and electron-donor $(\gamma-)$ parameter. The surface energy data of fillers and polypropylene in this paper which were obtained from various literatures are given in Table 1 [18-22]. A total expression for the interfacial tension between reinforcement and matrix is given by Giese and Van Oss as follows [23-25]:

$$
\begin{aligned}
\gamma_{i j}= & \gamma_{i}+\gamma_{j} \\
& -2\left(\left(\gamma_{i}^{\mathrm{LW}} \gamma_{j}^{\mathrm{LW}}\right)^{1 / 2}+\left(\gamma_{i}^{+} \gamma_{j}^{-}\right)^{1 / 2}+\left(\gamma_{i}^{-} \gamma_{j}^{+}\right)^{1 / 2}\right),
\end{aligned}
$$

where LW is Lipschitz-van der Waals forces, - and + are polar forces, and $i$ and $j$ are two interacting phases. The thermodynamical work of adhesion (WA) between two interacting phases is another way to quantify the interfacial strength. Owens and Wendt have suggested applying the geometric mean of the polar and the nonpolar interactions for the calculation of WA, which leads to the following [5, 23, 24]:

$$
\mathrm{WA}=2\left(\gamma_{i}^{\mathrm{LW}} \gamma_{j}^{\mathrm{LW}}\right)^{1 / 2}+2\left(\gamma_{i}^{\mathrm{AB}} \gamma_{j}^{\mathrm{AB}}\right)^{1 / 2}
$$

Following the above equations, the interfacial tension and thermodynamical work of adhesion between the filler and matrix interfaces were calculated and given in Table 2.

Table 1 presents surface energy parameters of PP and fillers, which determined their wettability. The main reason of liquid can spread on solid surface spontaneously is the surface energy of liquid is smaller than that of solid surface. The greater difference of surface energy between solid and liquid, the better spreading of liquid on solid surface [26, 27]. As apparent from Table 1, high surface energy of the heavy calcium carbonate provides an opportunity for the low $\gamma \mathrm{PP}$ matrix to completely wet its surface and have intimate interactions between two phases. The surface energy of fly ash is lower than that of PP, which made PP harder to wet its surface. This was reflected in the depressed flexural modulus and flexural strength at the high level of fly ash content. As can be seen from Table 2, the theoretical values of the interfacial surface energy and WA of PP-heavy calcium carbonate interface are higher than those of PP-straw, PP-fly ash, and $\mathrm{PP}-\mathrm{SiO}_{2}$ interface. The higher interfacial adhesion can promote better bonding and mechanical interlocking between the reinforcement and matrix [26]. Thereby the heavy calcium carbonate/WS/PP composites have better properties in flexural modulus and flexural strength. Though $\mathrm{PP}-\mathrm{SiO}_{2}$ also shows good value of $\gamma$ and WA, the properties of flexural modulus and flexural strength did not improve markedly. This result was expected due to the fact that the compression molding could not make inorganic fillers evenly distributed. The hydrophilic nature of the WS fiber and inorganic filler and the contrasting hydrophobic nature of PP matrix exacerbate the agglomeration problem, resulting in the strength concentration and the reduction of bending property.

3.4. Water Absorption. Plots of water absorption versus immersion time for WS and inorganic filler reinforced PP composites were presented in Figure 4. The presence of WS dramatically increases the water absorption of WS/PP when compared to $20 \mathrm{wt}$.\% WS reinforced PP composites. This phenomenon can be attributed to the hydrophilic nature of WS fiber, which leads to absorbing much water depending on the environmental condition. The chemical reason for this is due to the presence of hydroxyl groups in the cellulose structure which attract water molecules and bind with them through hydrogen bonding as reported in the literatures $[28,29]$. It can be observed from Figures 4(a), 4(b), and $4(c)$, that the amount of water absorption decreased by increasing the loading levels of inorganic fillers. Because of constant WS and inorganic filler content (50wt.\%) in all formulations, the different water absorption among all manufactured composites could be attributed to the role of inorganic filler.

Compared to WS/PP composites with $50 \mathrm{wt} . \%$ WS, the water absorption of composites has been, respectively, reduced by $1.8 \%$ (fly ash), $25.8 \%$ (heavy calcium carbonate), and $42.4 \%\left(\mathrm{SiO}_{2}\right)$, when the inorganic filler loading level increased to $25 \mathrm{wt}$. $\%$ (Figure $4(\mathrm{~d})$ ). The introduction of fly ash did not exhibit a significant effect on improving the water absorption resistance of WS/PP composite. Because of the weak adhesion between PP-fly ash and PP-WS (Table 2), more holes could be found in Figure 1(d), through where water seeped into the internal material results in the increment 


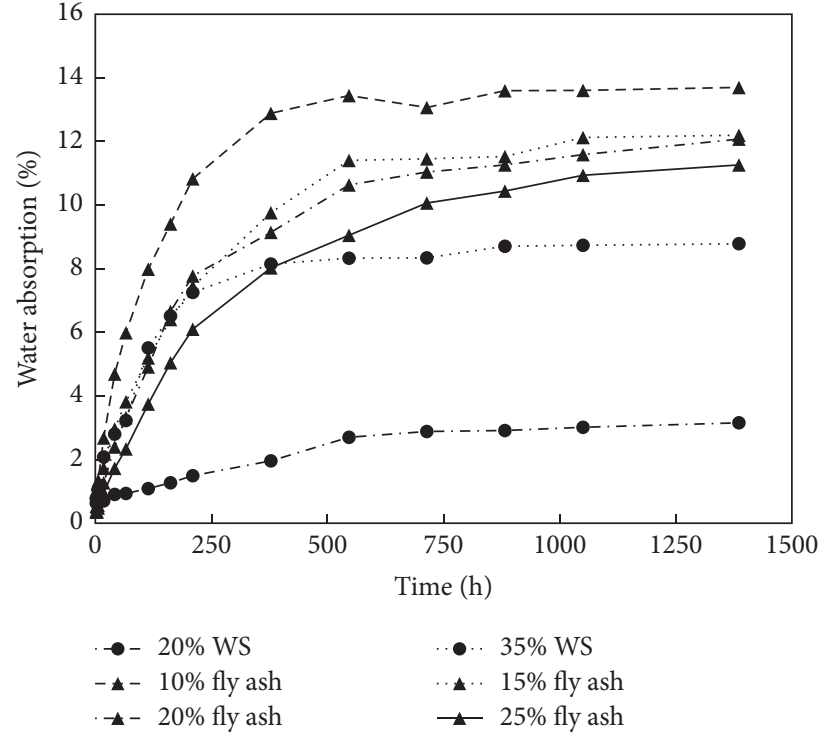

(a)

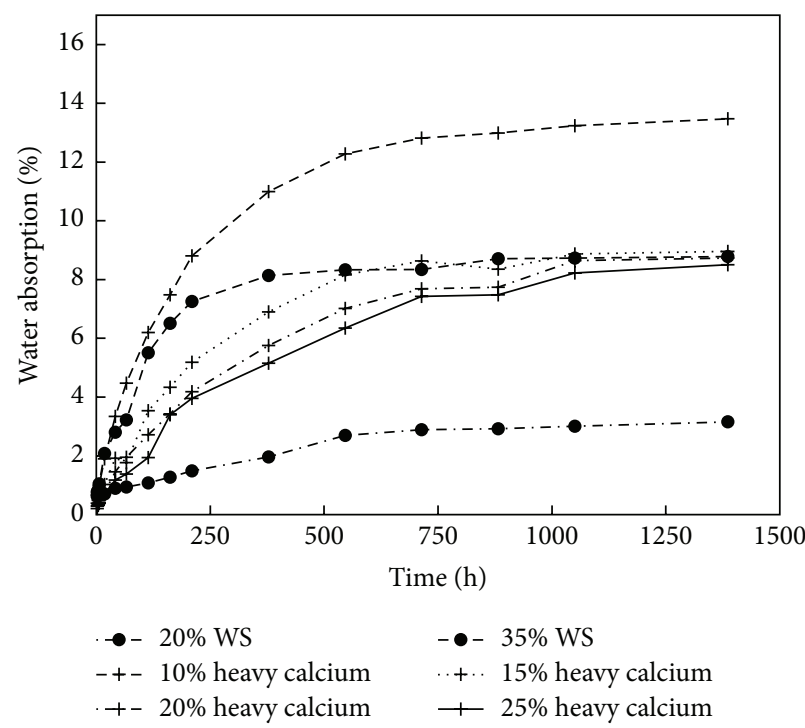

(c)

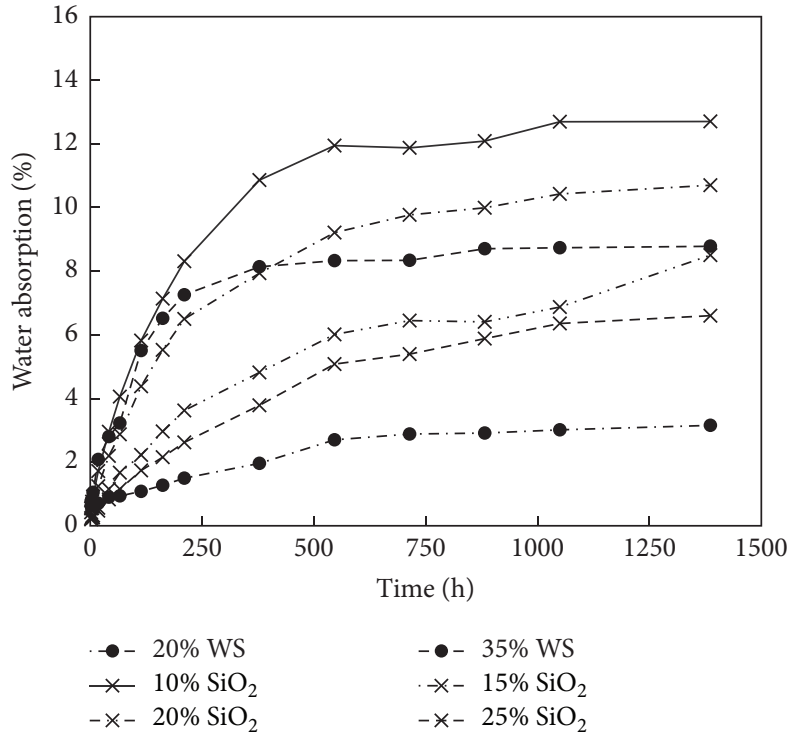

(b)

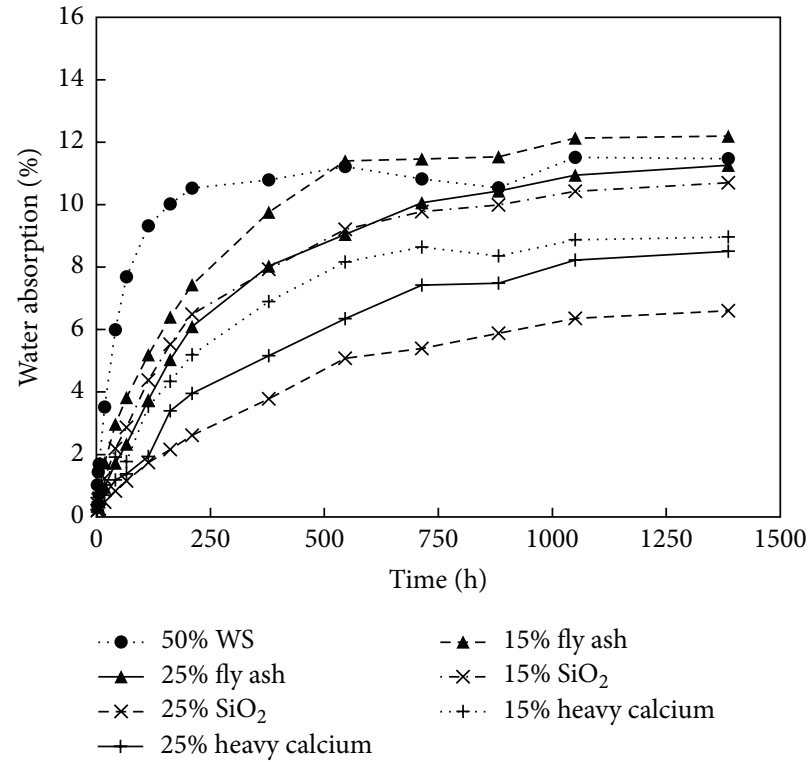

(d)

FIGURE 4: Water absorption of WS and inorganic filler reinforced PP composites.

of water absorption. However, the incorporation of $\mathrm{SiO}_{2}$ effectively decreases the water absorption for $\mathrm{SiO}_{2}$ filled WS/PP composites compared to unfilled WS/PP composites. The maximum water absorption decreases continuously with increasing $\mathrm{SiO}_{2}$ content. This result was expected due to the presence of $\mathrm{SiO}_{2}$ in the WS/PP composites which acts as a barrier medium that hinders the water flow into the composites from all directions, which decreased equilibrium water content [30,31]. Similar observation has been made by Alamri and Low [30] on nanoclay filled recycled cellulose fiber reinforced epoxy hybrid nanocomposites. Their results showed that water absorption decreased with clay content increased.
Three different mechanisms have been proposed for moisture penetration into the composite $[32,33]$. The main process is the diffusion of water molecules inside the microgaps between the polymer chains. The other two mechanisms are capillary transport of water into the gaps and flaws created at the interface of fiber and polymer matrix because of incomplete wettability and impregnation and also diffusion of water molecules into the microcracks formed in the matrix during the compounding process [34]. There are three categories for diffusion behaviour. In case I, the rate of diffusion is much less than that of the polymer segment mobility (relaxation). Penetrant mobility is much greater than the polymer relaxation in case II and the diffusion is 


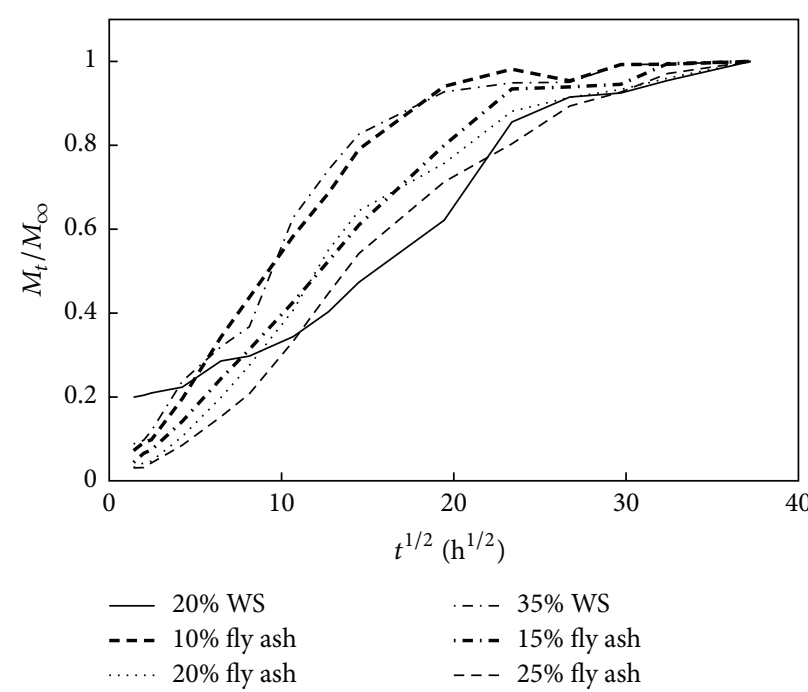

(a)

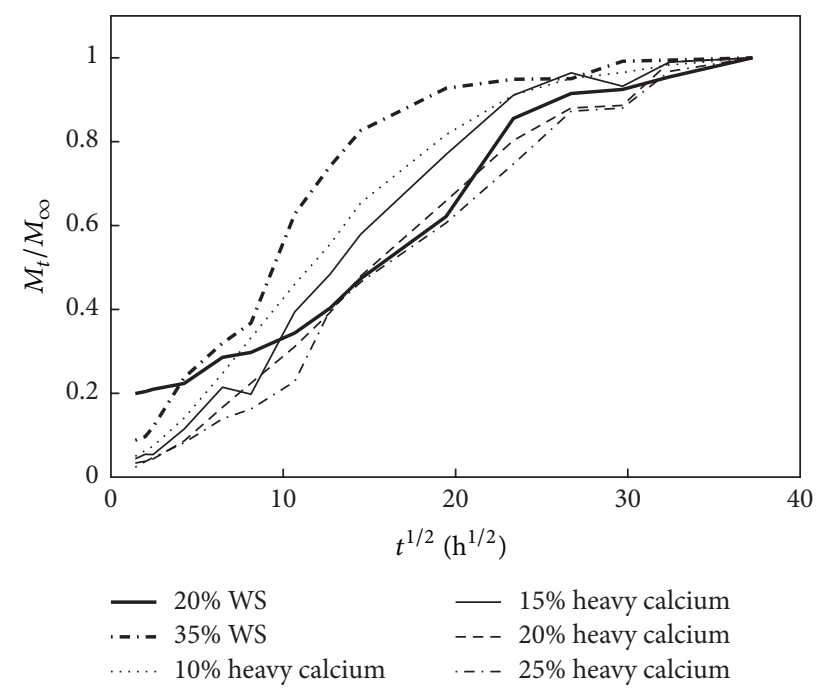

(c)

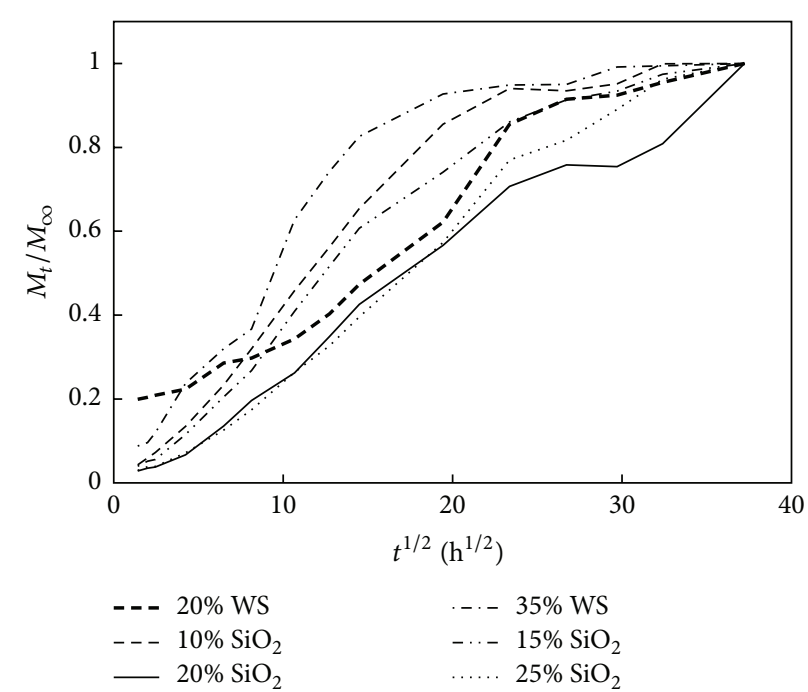

(b)

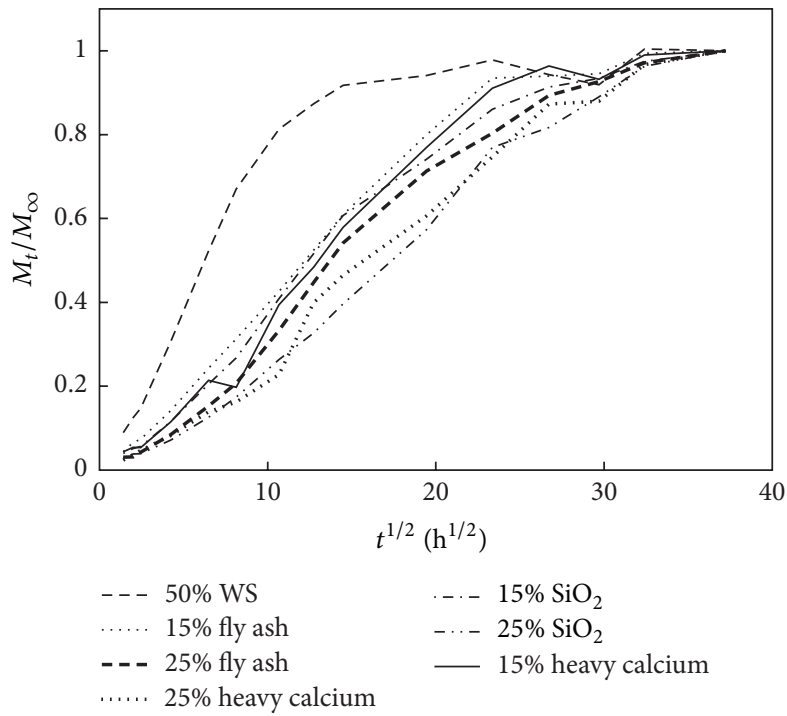

(d)

FIGURE 5: Curves of $M_{t} / M_{\infty}$ versus $t^{1 / 2}$ of WS and inorganic filler reinforced PP composites.

characterized by the development of the boundary between swollen outer part and the inner core of the polymer. NonFickian or anomalous diffusion occurs when the penetrant mobility and polymer segment mobility are comparable [3436]. This is an intermediate behaviour between cases I and II. These cases can theoretically be distinguished by [36]

$$
\frac{M_{t}}{M_{\infty}}=k t^{n}
$$

where $M_{t}$ is the water absorption at time $t, M_{\infty}$ is water absorption at the saturation point, and $k$ and $n$ are constants. The value of $n$ is different for the cases as follows: in Fickian diffusion $n=0.5$, relaxation $n=0.5$, relaxation $n>0.5$, and anomalous transport $0.5<n<1$. The coefficients ( $n$ and $k$ ) are calculated from slope and intercept of the log plot of
$M_{t} / M_{\infty}$ versus time which can be drawn from experimental data.

The diffusion coefficient is the most important parameter of Fick's model and shows the ability of water molecules to penetrate inside the composite structures. At early stages and small times (typically $M_{t} / M_{\infty} \leq 0.5$ ), the diffusion process is presented as follows [37]:

$$
\frac{M_{t}}{M_{\infty}}=\frac{4 t^{1 / 2}}{\left(D_{t} / \pi L^{2}\right)^{1 / 2}},
$$

where $L$ is the thickness of the specimen and $D$ is the diffusion coefficient. The data were plotted as $M_{t} / M_{\infty}$ against $t^{1 / 2}$ (Figure 5), and the diffusion coefficients were obtained from the slopes of the linear part of the plots using the less-squares method which were given in Figure 6. It can be observed that the diffusivity of WS/PP composites increased from $6.6 \times$ 


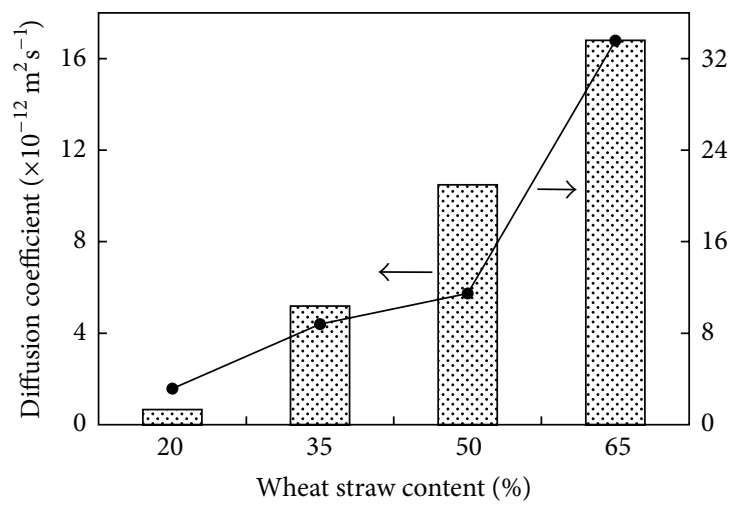

(a)

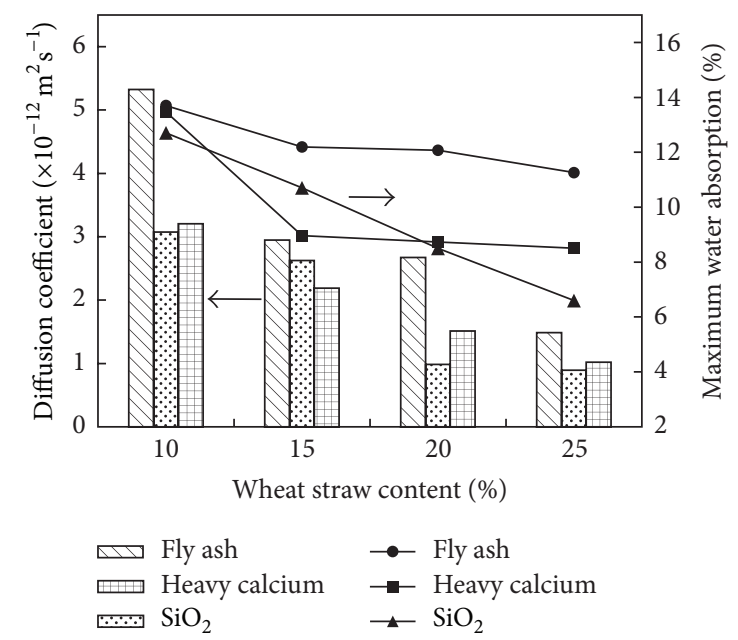

(b)

FIGURE 6: Water diffusion coefficients and maximum water absorption of WS filled PP composites (a) and WS and inorganic filler reinforced PP composites (b).

$10^{-12} \mathrm{~m}^{2} / \mathrm{s}$ to $1.7 \times 10^{-11} \mathrm{~m}^{2} / \mathrm{s}$ after the addition of WS fiber from 20 to $65 \mathrm{wt} . \%$. It can also be observed that the maximum water absorption increased significantly (from about 3\% to over 33\%) by introduction of WS fiber (from $20 \mathrm{wt} \%$ to 65 wt.\%) in it. This result was expected due to the hydrophilic nature of WS fiber; the overall performance of WS/PP composites was penalized when exposed to water. WS fiber was assumed to be encapsulated in the PP matrix, which was not completely valid, especially when the filler content is above 40 wt.\% [38]. The high WS loading level (65 wt.\% WS) further contributed to the activeness of capillarity and transport via microcracks leading to more water being seeped into the composites. The capillarity mechanism involves the flow of water molecules along fiber-matrix interfaces and a process of diffusion through the matrix [39]. In addition, Tamrakar and Lopez-Anido [40] stated that, with higher percentage of filler content, the fillers form extended and contacting chains, which enhances the penetration of water into the core of the material, resulting in increased moisture content of the overall material. Diffusion coefficient and maximum water absorption of the composite exhibited a decreasing trend with increasing inorganic filler in the WS/PP composites, in which WS/PP with $\mathrm{SiO}_{2}$ and heavy calcium carbonate presented good properties in the reduction of diffusion coefficient and maximum water absorption. This might be attributed to the fact that high interfacial adhesion of PP$\mathrm{SiO}_{2}$ and PP-heavy calcium carbonate enhanced the bonding performance between the reinforcement and matrix, which slowed capillarity and water molecules transport penetrating into the composites.

3.5. Thermal Expansion Properties. The LCTE values over two temperature ranges (from $20^{\circ} \mathrm{C}$ to $-13^{\circ} \mathrm{C}$ and from $-13^{\circ} \mathrm{C}$ to $60^{\circ} \mathrm{C}$ ) are illustrated in Figure 7 as a function of wheat straw filler content levels for composites. Wheat straw fiber content at the $20 \%$ level causes the largest LTEC values, which are 110.9 and $107.1 \times 10^{-6 \circ} \mathrm{C}$, respectively. At the $65 \%$ level, the LTEC values reduced by $66.9 \%$ and $69.3 \%$, respectively, which are 66.5 and $63.2 \times 10^{-6} /{ }^{\circ} \mathrm{C}$. The thermal expansion of composites decreased with the increase of wheat straw loading level. The increasing of wheat straw fiber could limit the deformation of polypropylene molecular chain and hinder the flow ability of plastic matrix, which might be the reason for lower LCTE value. When the total filler content remains at $50 \%$, three sorts of inorganic filler (fly ash, silicon dioxide, and heavy calcium) were used to gradually replace the content of the organic filler, respectively.

Figure 7 shows measured LCTE values as a function of inorganic filler content for wheat straw filled R-PP. The temperature range of $20^{\circ} \mathrm{C}$ to $-13^{\circ} \mathrm{C}$ had the largest LCTE values at all inorganic content levels. Heavy calcium and silicon dioxide can obviously reduce the LCTE value of composite. LCTE decreased with increased heavy calcium and silicon dioxide content. When the $25 \%$ inorganic filler was filled, composites revealed the smallest LCTE values. Compared with 50\% WS filled PP composites, the LCTE values decreased by $33.9 \%$ and $32.8 \%$, respectively, at $25 \%$ heavy calcium loading level. And when $25 \%$ silicon dioxide was filled into WS/PP composites, this values decreased by $25.6 \%$ and $27.8 \%$ respectively. With the increased fly ash content, the LCTE of filled composites showed unapparent influence on reducing LCTE value. The reason might be the poor compatibility of fly ash, wheat straw fiber, and the PP matrix, which made fiber and fly ash cannot limit the deformation of the matrix.

\section{Conclusions}

The present study has shown that recycled PP based hybrid composites consisting of WS and inorganic fillers can be fabricated and achieved a balance of properties such as high 


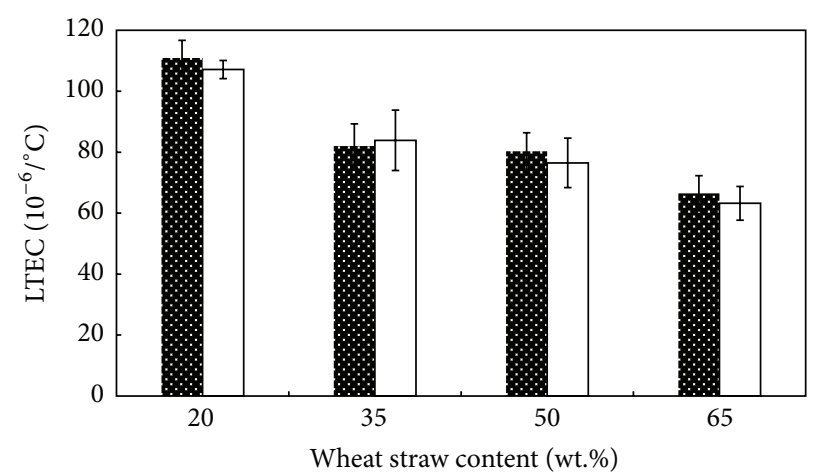

s $20^{\circ} \mathrm{C}--13^{\circ} \mathrm{C}$ $\square-13^{\circ} \mathrm{C}-60^{\circ} \mathrm{C}$

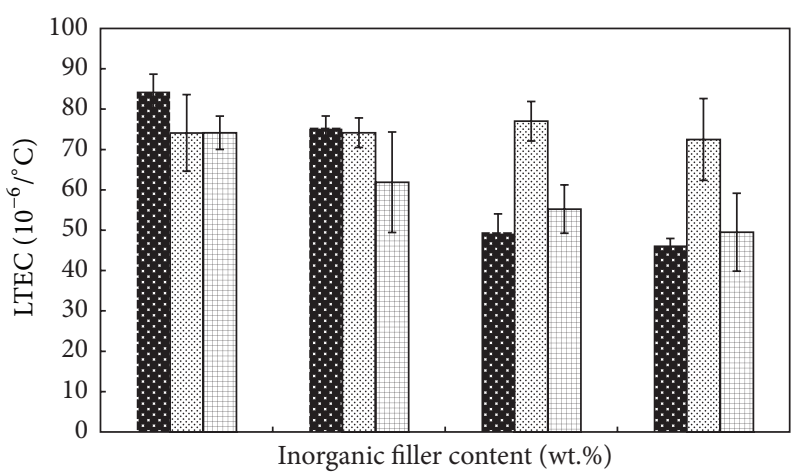

Meavy calcium

[. Silicon dioxide

曰 Fly ash

(a)

(b)

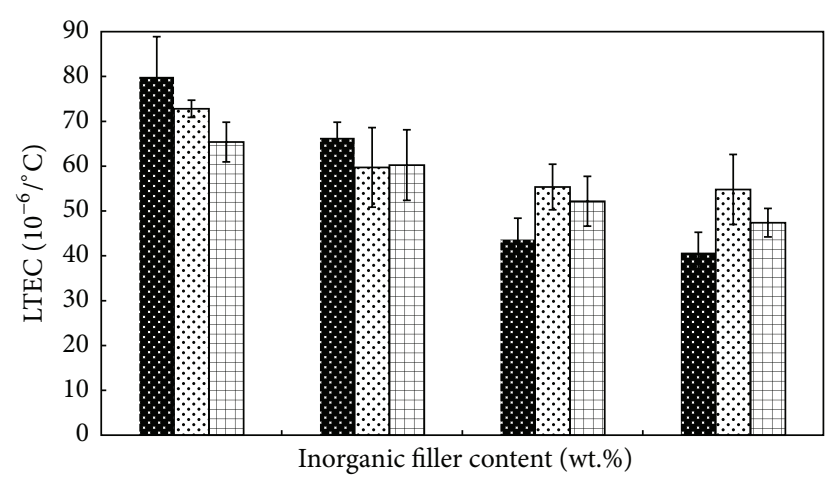

. Heavy calcium

๑. Silicon dioxide

$\square$ Fly ash

(c)

FIgURE 7: Thermal expansion properties of WS filled PP composites (a) and WS and inorganic filler reinforced PP composites (b) 20- $-13^{\circ} \mathrm{C}$; (c) $-13-60^{\circ} \mathrm{C}$.

stiffness, good dimension stability, acceptable thermal expansion properties, and low price. The following conclusions could be drawn from the results of the present study:

(1) The stiffness of WS/PP composite increased with the addition of WS and the strength concentration caused by fiber aggregation, thus resulting in the reduced toughness of the composite. The flexural modulus and flexural strength of WS/PP composites were both reduced when reinforced with three kinds of inorganic fillers, respectively, which was possibly due to the poor interphase adhesion as observed in SEM micrographs. The increase of rigid inorganic filler further decreases the impact strength.

(2) The high surface energy of heavy calcium carbonate due to its high acidic character provides an opportunity of better PP- heavy calcium carbonate interfacial interactions compared to PP-straw, PP-fly ash, and $\mathrm{PP}-\mathrm{SiO}_{2}$ interface.

(3) The water absorption at saturation increased markedly by introduction of WS fiber in it. The hybrid system of WS and inorganic fillers showed better water absorption compared to those WS/PP composites without inorganic fillers.
(4) The thermal expansion of composites decreased with the increase of WS loading. Heavy calcium and $\mathrm{SiO}_{2}$ can obviously reduce the LCTE value of composite. At the 25\% inorganic filler content, composites had the smallest LCTE values.

\section{Competing Interests}

The authors declare that they have no competing interests regarding the publication of this paper.

\section{Authors' Contributions}

Runzhou Huang and Min Yu contributed equally to the writing of this paper.

\section{Acknowledgments}

The authors would like to thank the financial support from Natural Science Foundation of China (contract Grant nos. 
31300482 and 31500483), Natural Science Foundation of Jiangsu Province (BK20130966), National Science \& Technology Pillar Program (2011BAD20B202-2), and National State Bureau of Forestry 948 Plan of China (Grant no. 2014-49).

\section{References}

[1] N. Ayrilmis, T. Dundar, A. Kaymakci, F. Ozdemir, and J. H. Kwon, "Mechanical and thermal properties of wood-plastic composites reinforced with hexagonal boron nitride," Polymer Composites, vol. 35, no. 1, pp. 194-200, 2014.

[2] R. Huang, Y. Zhang, X. Xu, D. Zhou, and Q. Wu, "Effect of hybrid mineral and bamboo fillers on thermal expansion behavior of bamboo fiber and recycled polypropylene-polyethylene composites," BioResources, vol. 7, no. 4, pp. 4563-4574, 2012.

[3] A. A. Klyosov, Wood-Plastic Composites, John Wiley \& Sons, 2007.

[4] S.-Y. Lee, I.-A. Kang, G.-H. Doh, H.-G. Yoon, B.-D. Park, and Q. Wu, "Thermal and mechanical properties of wood flour/talcfilled polylactic acid composites: effect of filler content and coupling treatment," Journal of Thermoplastic Composite Materials, vol. 21, no. 3, pp. 209-223, 2008.

[5] S. Singh, A. K. Mohanty, and M. Misra, "Hybrid bio-composite from talc, wood fiber and bioplastic: Fabrication and characterization," Composites Part A: Applied Science and Manufacturing, vol. 41, no. 2, pp. 304-312, 2010.

[6] A. Nourbakhsh, F. F. Baghlani, and A. Ashori, "Nano- $\mathrm{SiO}_{2}$ filled rice husk/polypropylene composites: physico-mechanical properties," Industrial Crops and Products, vol. 33, no. 1, pp. 183$187,2011$.

[7] S. Kazemi Najafi, "Use of recycled plastics in wood plastic composites-a review," Waste Management, vol. 33, no. 9, pp. 1898-1905, 2013.

[8] L. Han, Q. Yan, X. Liu, and J. Hu, "Straw resources and their utilization in China," Transactions of the Chinese Society of Agricultural Engineering, vol. 18, no. 3, pp. 87-91, 2002.

[9] J. G. Gwon, S. Y. Lee, and J. H. Kim, "Thermal degradation behavior of polypropylene base wood plastic composites hybridized with metal (aluminum, magnesium) hydroxides," Journal of Applied Polymer Science, vol. 131, no. 7, Article ID 40120, 2014.

[10] A. Schirp, B. Plinke, and D. Napolow, "Effectiveness of organic and inorganic pigments for mass colouration of thermomechanical pulp used in wood-plastic composites," European Journal of Wood and Wood Products, vol. 73, no. 1, pp. 5-16, 2015.

[11] D. P. Kamdem, H. Jiang, W. Cui, J. Freed, and L. M. Matuana, "Properties of wood plastic composites made of recycled HDPE and wood flour from CCA-treated wood removed from service," Composites Part A: Applied Science and Manufacturing, vol. 35, no. 3, pp. 347-355, 2004.

[12] S. Jarusombuti and N. Ayrilmis, "Surface characteristics and overlaying properties of flat-pressed wood plastic composites," European Journal of Wood and Wood Products, vol. 69, no. 3, pp. 375-382, 2011.

[13] N. Ayrilmişs, J. T. Benthien, and H. Thoemen, "Effects of formulation variables on surface properties of wood plastic composites," Composites Part B: Engineering, vol. 43, no. 2, pp. 325-331, 2012.

[14] Y. Xie, C. A. S. Hill, Z. Xiao, H. Militz, and C. Mai, "Silane coupling agents used for natural fiber/polymer composites: a review," Composites Part A: Applied Science and Manufacturing, vol. 41, no. 7, pp. 806-819, 2010.
[15] M. M. Kabir, H. Wang, K. T. Lau, and F. Cardona, "Chemical treatments on plant-based natural fibre reinforced polymer composites: an overview," Composites Part B: Engineering, vol. 43, no. 7, pp. 2883-2892, 2012.

[16] M. Lewin, A. Mey-Marom, and R. Frank, "Surface free energies of polymeric materials, additives and minerals," Polymers for Advanced Technologies, vol. 16, no. 6, pp. 429-441, 2005.

[17] M. C. Van der Leeden and G. Frens, "Surface properties of plastic materials in relation to their adhering performance," Advanced Engineering Materials, vol. 4, pp. 280-289, 2002.

[18] H. Schönherr, Z. Hruska, and G. J. Vancso, "Surface characterization of oxyfluorinated isotactic polypropylene films: scanning force microscopy with chemically modified probes and contact angle measurements," Macromolecules, vol. 31, no. 11, pp. 36793685, 1998.

[19] E. M. Harnett, J. Alderman, and T. Wood, “The surface energy of various biomaterials coated with adhesion molecules used in cell culture," Colloids and Surfaces B: Biointerfaces, vol. 55, no. 1, pp. 90-97, 2007.

[20] X. Chen, M. Farber, Y. Gao, I. Kulaots, E. M. Suuberg, and R. H. Hurt, "Mechanisms of surfactant adsorption on non-polar, air-oxidized and ozone-treated carbon surfaces," Carbon, vol. 41, no. 8, pp. 1489-1500, 2003.

[21] S. Bargir, S. Dunn, B. Jefferson, J. Macadam, and S. Parsons, "The use of contact angle measurements to estimate the adhesion propensity of calcium carbonate to solid substrates in water," Applied Surface Science, vol. 255, no. 9, pp. 4873-4879, 2009.

[22] N. Boquillon, G. Elbez, and U. SchÖnfeld, "Properties of wheat straw particleboards bonded with different types of resin," Journal of Wood Science, vol. 50, no. 3, pp. 230-235, 2004.

[23] Z. Li, R. F. Giese, and C. J. Van Oss, "Surface thermodynamic properties of synthetic hydrotalcite compounds," Langmuir, vol. 10, no. 1, pp. 330-333, 1994.

[24] R. F. Giese Jr., W. Wu, and C. J. Van Oss, "Surface and electrokinetic properties of clays and other mineral particles, untreated and treated with organic or inorganic cations," Journal of Dispersion Science and Technology, vol. 17, no. 5, pp. 527-547, 1996.

[25] Z. Li, R. F. Giese, C. J. Van Oss, J. Yvon, and J. Cases, "The surface thermodynamic properties of talc treated with octadecylamine," Journal of Colloid and Interface Science, vol. 156, no. 2, pp. 279-284, 1993.

[26] A. W. Adamson and A. P. Gast, Physical Chemistry of Surfaces, 1967.

[27] D. K. Owens and R. Wendt, "Estimation of the surface free energy of polymers," Journal of Applied Polymer Science, vol. 13, no. 8, pp. 1741-1747, 1969.

[28] H. J. Kim and D. W. Seo, "Effect of water absorption fatigue on mechanical properties of sisal textile-reinforced composites," International Journal of Fatigue, vol. 28, no. 10, pp. 1307-1314, 2006.

[29] T.-T. Doan, H. Brodowsky, and E. Mäder, "Jute fibre/polypropylene composites II. Thermal, hydrothermal and dynamic mechanical behaviour," Composites Science and Technology, vol. 67, no. 13, pp. 2707-2714, 2007.

[30] H. Alamri and I. M. Low, "Effect of water absorption on the mechanical properties of nanoclay filled recycled cellulose fibre reinforced epoxy hybrid nanocomposites," Composites Part A: Applied Science \& Manufacturing, vol. 44, no. 1, pp. 23-31, 2013. 
[31] B. K. Deka and T. K. Maji, "Study on the properties of nanocomposite based on high density polyethylene, polypropylene, polyvinyl chloride and wood," Composites Part A: Applied Science and Manufacturing, vol. 42, no. 6, pp. 686-693, 2011.

[32] A. Espert, F. Vilaplana, and S. Karlsson, "Comparison of water absorption in natural cellulosic fibres from wood and one-year crops in polypropylene composites and its influence on their mechanical properties," Composites Part A: Applied Science and Manufacturing, vol. 35, no. 11, pp. 1267-1276, 2004.

[33] R. Kahraman and B. Abu-Sharkh, "Moisture absorption behavior of palm/polypropylene composites in distilled water and sea water," International Journal of Polymeric Materials and Polymeric Biomaterials, vol. 56, no. 1, pp. 43-53, 2007.

[34] M. Razavi-Nouri, F. Jafarzadeh-Dogouri, A. Oromiehie, and A. E. Langroudi, "Mechanical properties and water absorption behaviour of chopped rice husk filled polypropylene composites," Iranian Polymer Journal, vol. 15, no. 9, pp. 757-766, 2006.

[35] Q. Lin, X. Zhou, and G. Dai, "Effect of hydrothermal environment on moisture absorption and mechanical properties of wood flour-filled polypropylene composites," Journal of Applied Polymer Science, vol. 85, no. 14, pp. 2824-2832, 2002.

[36] G. Marom, "The role of water transport in composite materials," in Polymer Permeability, pp. 341-374, Springer, 1985.

[37] A. Ram, Fundamentals of Polymer Engineering, Springer, Boston, Mass, USA, 1997.

[38] A. Klyosov, Wood Plastic Composites, John Wiley \& Sons, Hoboken, NJ, USA, 2007.

[39] I. Ghasemi and B. Kord, "Long-term water absorption behaviour of polypropylene/wood flour/organoclay hybrid nanocomposite," Iranian Polymer Journal, vol. 18, no. 9, pp. 683-691, 2009.

[40] S. Tamrakar and R. A. Lopez-Anido, "Water absorption of wood polypropylene composite sheet piles and its influence on mechanical properties," Construction \& Building Materials, vol. 25, no. 10, pp. 3977-3988, 2011. 

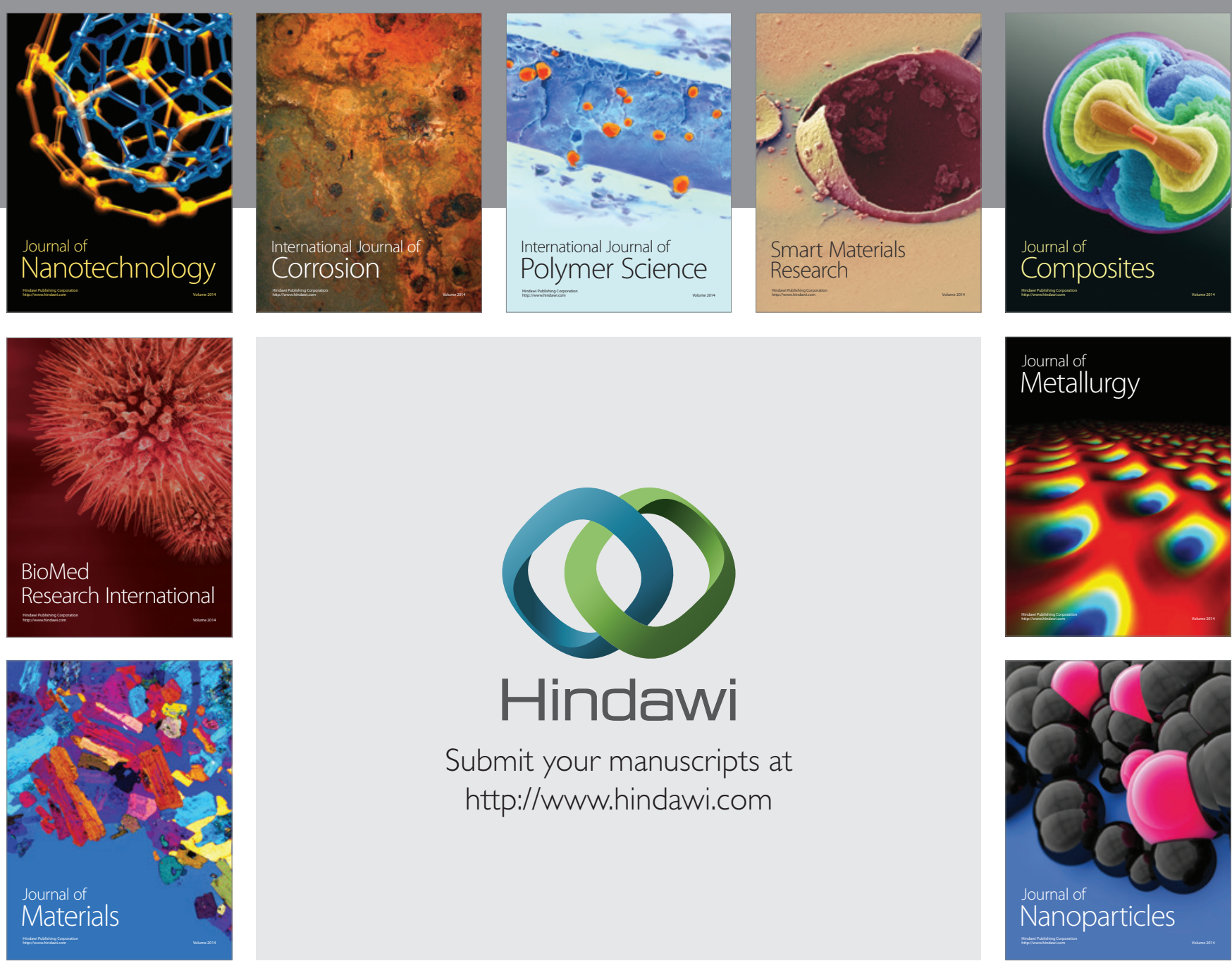

\section{Hindawi}

Submit your manuscripts at

http://www.hindawi.com

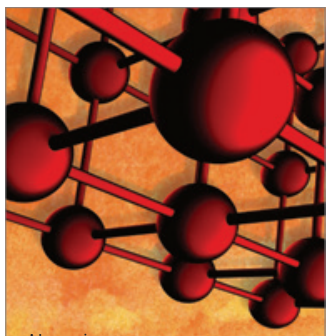

Materials Science and Engineering
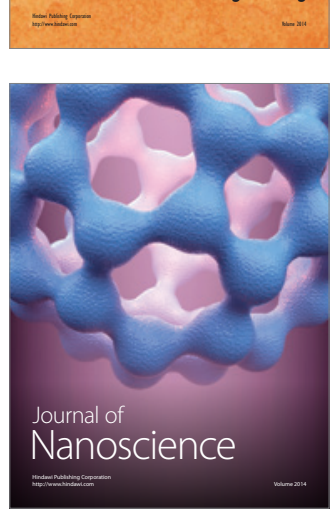
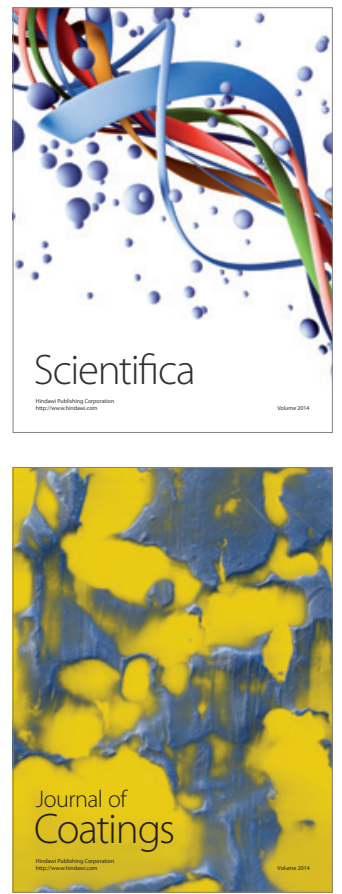
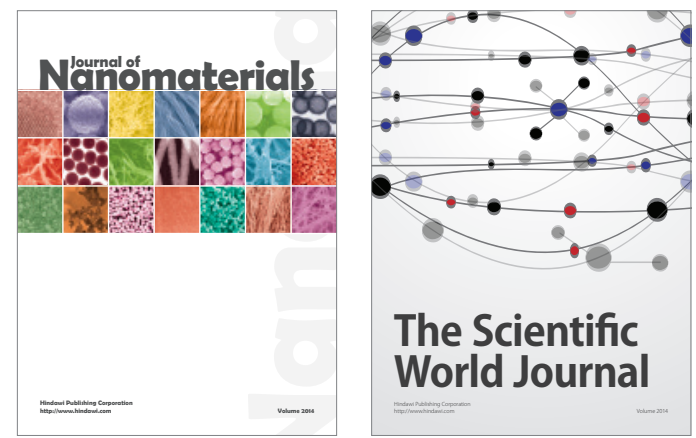

The Scientific World Journal
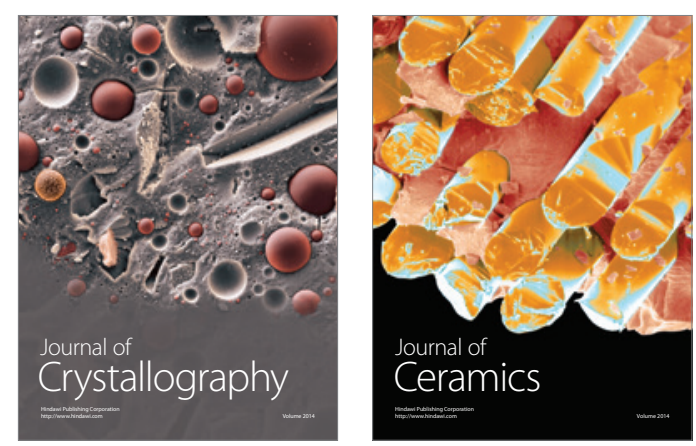
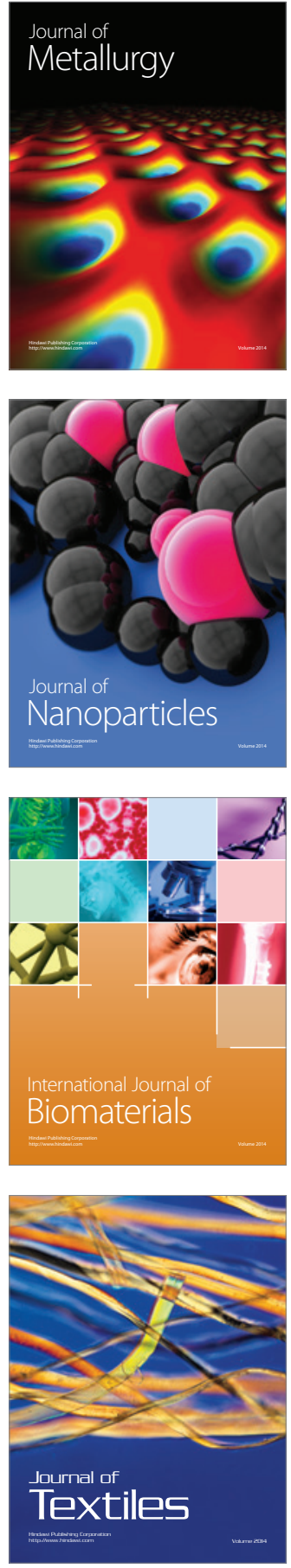